This item was submitted to Loughborough's Research Repository by the author.

Items in Figshare are protected by copyright, with all rights reserved, unless otherwise indicated.

\title{
The influence of local skin temperature on the sweat glands maximum ion reabsorption rate
}

PLEASE CITE THE PUBLISHED VERSION

https://doi.org/10.1007/s00421-018-04059-5

\section{PUBLISHER}

(C) Springer

VERSION

AM (Accepted Manuscript)

\section{PUBLISHER STATEMENT}

This is a post-peer-review, pre-copyedit version of an article published in European Journal of Applied Physiology. The final authenticated version is available online at: https://doi.org/10.1007/s00421-018-04059-5

\section{LICENCE}

CC BY-NC-ND 4.0

\section{REPOSITORY RECORD}

Gerrett, Nicola, Tatsuro Amano, George Havenith, Yoshimitsu Inoue, and N. Kondo. 2019. "The Influence of Local Skin Temperature on the Sweat Glands Maximum Ion Reabsorption Rate". Loughborough University. https://hdl.handle.net/2134/36918. 
1 The influence of local skin temperature on the sweat glands maximum ion 2 reabsorption rate

4 Gerrett, $\mathbf{N}^{1}$. Amano, $\mathbf{T}^{2}$. Havenith, $\mathbf{G}^{3}$. Inoue, $\mathbf{Y}^{4}$. \& Kondo, $\mathbf{N}^{1}$. 5

$6{ }^{1}$ Laboratory for Applied Human Physiology, Graduate School of Human Development 7 and Environment, Kobe University, Kobe, Japan

$8{ }^{2}$ Laboratory for Exercise and Environmental Physiology, Faculty of Education, Niigata 9 University, Niigata, Japan

103 Environmental Ergonomics Research Centre, Loughborough Design School, 11 Loughborough University, Loughborough, United Kingdom.

124 Laboratory for Human Performance Research, Osaka International University, 13 Osaka, Japan

Address for correspondence: Narihiko Kondo, Ph.D., Laboratory for Applied Human 16 Physiology, Graduate School of Human Development and Environment, Kobe University, 17 3-11 Tsurukabuto, Nada-Ku, Kobe 657-8501, Japan, Tel and Fax: +81- 78-803-7816, 18 Email: kondo@kobe-u.ac.jp 
30 Acknowledgements

31 We thank our participants for volunteering their time. We also thank Drs S. Koga and D.

32 Okushima for their insightful comments during the preparation of this manuscript. Finally,

33 we thank Dr Koji Sato for his assistance with aldosterone analysis.

34

\section{Grants}

36 This study was supported by a Grant-in-Aid for Scientific Research (16H04851 and 37 17H0253) from the Japan Society for the Promotion of Science from the Ministry of 38 Education, Culture, Sports, Science, and Technology of Japan.

39

40 Disclosures

41 The authors declare no conflicts of interest, financial or otherwise.

42

43

44

45

46

47

48

49

50

51

52

53 


\section{Abstract}

\section{Purpose}

56 Changes in mean skin temperature $\left(\mathrm{T}_{\mathrm{sk}}\right)$ have been shown to modify the maximum rate of 57 sweat ions reabsorption. This study aims to extend this knowledge by investigating if 58 modifications could also be caused by local $\mathrm{T}_{\mathrm{sk}}$.

\section{Methods}

60 The influence of local $\mathrm{T}_{\mathrm{sk}}$ on the sweat glands maximum ion reabsorption rates was 61 investigated in 10 healthy volunteers (3 female and 7 male; $20.8 \pm 1.2 \mathrm{yrs}, 60.4 \pm 7.7 \mathrm{~kg}$, $62 \quad 169.4 \pm 10.4 \mathrm{~cm}$ ) during passive heating (water perfused suit and lower leg water 63 immersion). In two separate trials, in a randomised order, one forearm was always 64 manipulated to $33^{\circ} \mathrm{C}$ (Neutral), whilst the other was manipulated to either $30^{\circ} \mathrm{C}(\mathrm{Cool})$ or $6536^{\circ} \mathrm{C}\left(\right.$ Warm) using water perfused patches. Oesophageal temperature $\left(\mathrm{T}_{\mathrm{es}}\right)$, forearm $\mathrm{T}_{\mathrm{sk}}$, sweat rate (SR), galvanic skin conductance (GSC) and salivary aldosterone concentrations

67 were measured. The sweat glands maximum ion reabsorption rates were identified using 68 the $\Delta \mathrm{SR}$ threshold for an increasing $\Delta \mathrm{GSC}$.

\section{Results}

70 Thermal ( $\mathrm{T}_{\mathrm{es}}$ and body temperature $\left.\left(\mathrm{T}_{\mathrm{b}}\right)\right)$ and non-thermal responses (aldosterone) were 71 similar across all conditions $(\mathrm{p}>0.05)$. A temperature dependent response for the sweat 72 glands maximum ion reabsorption rates was evident between $30^{\circ} \mathrm{C}(0.18 \pm 0.10$ $\left.73 \mathrm{mg} / \mathrm{cm}^{2 /} \mathrm{min}\right)$ and $36^{\circ} \mathrm{C}\left(0.28 \pm 0.14 \mathrm{mg} / \mathrm{cm}^{2} / \mathrm{min}, \mathrm{d}=0.88, \mathrm{p}<0.05\right)$, but not for $7433^{\circ} \mathrm{C}\left(0.22 \pm 0.12 \mathrm{mg} / \mathrm{cm}^{2} / \mathrm{min}\right), \mathrm{d}=0.44$ and $\left.\mathrm{d}=0.36, \mathrm{p}>0.05\right)$.

\section{Conclusion}

76 The data indicates that small variations in local $\mathrm{T}_{\mathrm{sk}}$ may not affect the sweat glands

77 maximum ion reabsorption rates but when the local $\mathrm{T}_{\mathrm{sk}}$ increases by $>6^{\circ} \mathrm{C}$, ion reabsorption 78 rates also increase. 
79 Keywords: sweat ion regulation, sweat glands, skin temperature, aldosterone

80

81 Abbreviations

82 ANOVA analysis of variance

83 CFTR cystic fibrosis transmembrane channels

$84 \mathrm{Cl}^{-}$Chloride

85 CVC cutaneous vascular conductance (\%)

$86 \mathrm{ENaC}$ epithelial sodium channel

87 GSC galvanic skin conductance $(\mu \mathrm{S})$

88 HASG heat-activated sweat glands

89 HR heart rate (bpm)

$90 \mathrm{~K}+$ potassium

91 MAP mean arterial pressure (mmHG)

$92 \mathrm{Na}^{+}$sodium

93 SGO sweat gland output

94 SR sweat rate $\left(\mathrm{mg} / \mathrm{cm}^{2} / \mathrm{min}\right)$

$95 \mathrm{~T}_{\mathrm{b}}$ body temperature $\left({ }^{\circ} \mathrm{C}\right)$

$96 \mathrm{~T}_{\mathrm{es}}$ Oesophageal temperature $\left({ }^{\circ} \mathrm{C}\right)$

$97 \quad \mathrm{~T}_{\mathrm{sk}}$ skin temperature $\left({ }^{\circ} \mathrm{C}\right)$

$98 \dot{V} \mathrm{O}_{2 \max }$ maximum oxygen uptake $(\mathrm{ml} / \mathrm{kg} / \mathrm{min})$

99

100 Introduction

Sweating is an essential physiological function for maintaining thermal homeostasis

102 and the content of sweated ions important for maintaining epidermal barrier homeostasis

103 and antimicrobial function of the skin. Despite rapid developments in biosensor technology 
104 that aim to determine sweat rate and its ion concentration (Gao et al. 2018), our knowledge

105 of sweat ion regulation is limited. It is well established that when eccrine sweat glands are

106 stimulated, the secretory coil, located at the base of the sweat gland, forms an isotonic fluid

107 and as sweat traverses the straight duct ion reabsorption occurs; resulting in a hypotonic

108 sweat released on the skin surface (Sato 1977; Shamsuddin et al. 2005b). It has been

109 suggested that with an increasing sweat rate (SR) the secretion rate increases proportionally

110 faster than the reabsorption rate, resulting in a linear relationship between SR and sweat

$111 \mathrm{Na}^{+}$concentration (Buono et al. 2008). Whilst this may be the case there are numerous

112 studies providing evidence that the reabsorption rate can be enhanced, most notably

113 following heat acclimation whereby a reduction in sweated ions occurs despite an increased

114 sweat production (Buono et al. 2007; Amano et al. 2016). Furthermore, the maximum rate

115 of ion reabsorption has been shown to differ between habitually trained and sedentary

116 individuals and is also known to vary across the body (Amano et al. 2017). What regulates

117 eccrine sweat glands ion reabsorption remains unknown.

118 A regulatory mechanism that has been previously reported to affect the maximum

119 ion reabsorption rate is $\mathrm{T}_{\text {sk. }}$. The influence of $\mathrm{T}_{\mathrm{sk}}$ on sweat production is well established

120 (Nadel et al. 1971) but its impact on sweated ions is somewhat contradictory with studies

121 reporting an influential role (Johnson et al. 1944; Robinson et al. 1985) and others reporting

122 little or no effect (Bulmer and Forwell 1956). These earlier studies were primarily focused

123 on the concentration of sweated ions but more recently Shamsuddin et al. (2005a)

124 investigated the reabsorption of these ions, that ultimately affects the sweated ion

125 concentration. By changing the ambient conditions $\left(15^{\circ} \mathrm{C}\right.$ or $\left.25^{\circ} \mathrm{C}\right)$, Shamsuddin et al.

126 (2005a) manipulated mean $\mathrm{T}_{\mathrm{sk}}$ by approximately $3^{\circ} \mathrm{C}$ during an exercising protocol. The

127 result of which was a significantly lower ion reabsorption rate at a lower compared to higher

128 mean $\mathrm{T}_{\mathrm{sk}}\left(0.21 \pm 0.04\right.$ vs. $0.52 \pm 0.06 \mathrm{mg} / \mathrm{cm}^{2} / \mathrm{min}$, respectively). The inhibition of the 
sweat glands ion reabsorption capacity was associated with the temperature dependency of epithelial sodium channel $(\mathrm{ENaC})$ excitability and open probability (Chraïbi and Horisberger 2003). However, they did not report the local $\mathrm{T}_{\mathrm{sk}}$ where the ion reabsorption rates were measured and also only focused on the effects of low $\mathrm{T}_{\mathrm{sk}}\left(<31^{\circ} \mathrm{C}\right)$ on the sweat glands maximum ion reabsorption rates. Therefore, it is still unknown whether the maximum ion reabsorption rates are proportional to local changes in $T_{\text {sk }}$ systematically.

It is also necessary to determine the influence of local $\mathrm{T}_{\mathrm{sk}}$ on the sweat glands maximum ion reabsorption rates as there is cumulative evidence for regional differences in ion reabsorption rates, with the torso generally having a higher reabsorption rate than the extremities (Amano et al. 2017; Gerrett et al. 2018a). However these regional differences were also mirrored by regional differences in local $\mathrm{T}_{\mathrm{sk}}$. It would be advantageous then to investigate the influence of local $\mathrm{T}_{\mathrm{sk}}$ on the sweat glands ions reabsorption rate within temperatures ranges expected whilst sweating.

Shamsuddin et al. (2005a) speculated that higher $\mathrm{T}_{\mathrm{sk}}$ might enhance the responsive ability of the sweat glands to a given concentration of circulating aldosterone; a hormone considered to be a primary effector of sodium exchange at the sweat gland (Hegarty and Harvey 1998; Harvey and Higgins 2000). Aldosterone concentrations and other water regulatory hormones such as atrial natriuretic peptide, vasopressin and renin are higher during exercise and are considered to be exercise intensity dependent (Convertino et al. 1983; Freund et al. 1991; Yoshida et al. 2006). Shamsuddin et al. (2005a) employed an exercise protocol (cycling at $60 \% \dot{V} \mathrm{O}_{2 \max }$ ) sufficient enough for the release of these hormones; although their influence on sweat glands ion reabsorption is inconclusive (Yoshida et al. 2006; Hew-Butler et al. 2010, 2014). As such it is important to investigate the role of $\mathrm{T}_{\mathrm{sk}}$ on the sweat glands maximum ion reabsorption rates when hormonal responses associated with exercise are isolated. 
155 we aimed to manipulate local forearm $\mathrm{T}_{\mathrm{sk}}$ to elicit a cool $\left(30^{\circ} \mathrm{C}\right)$, neutral $\left(33^{\circ} \mathrm{C}\right)$ and warm

$156\left(36^{\circ} \mathrm{C}\right) \mathrm{T}_{\mathrm{sk}}$, with the latter reflecting typical $\mathrm{T}_{\mathrm{sk}}$ experienced during heat stress on the sweat 157 glands ion reabsorption. In order to minimise any non-thermoregulatory mechanisms

158 affecting sweat glands ion reabsorption rates the influence of local $\mathrm{T}_{\mathrm{sk}}$ on ion reabsorption

159 during a passive heating protocol was selected. We hypothesized that eccrine sweat glands 160 maximum ion reabsorption rates are temperature dependent, with maximum ion 161 reabsorption occurring at a higher sweat rate (SR) with a higher local $\mathrm{T}_{\mathrm{sk}}\left(36^{\circ} \mathrm{C}\right)$ compared 162 to neutral $\left(33^{\circ} \mathrm{C}\right)$ and $\operatorname{cool} \mathrm{T}_{\mathrm{sk}}\left(30^{\circ} \mathrm{C}\right)$.

\section{Methods}

Participants were informed about the study purpose and procedures prior to providing verbal and written consent. The Human Subjects Committee of the Graduate

167 School of Human Development and Environment at Kobe University (Japan) approved the 168 study (report no. 259), which conforms to the standards set out by the Declaration of 169 Helsinki (except for registration in a database).

170

171 Participants

172 Ten young healthy recreationally active participants ( 3 female and 7 male; $20.8 \pm$ $1731.2 \mathrm{yrs}, 60.4 \pm 7.7 \mathrm{~kg}, 169.4 \pm 10.4 \mathrm{~cm}$ ) were recruited for this study during winter in Japan 174 and thus were considered unacclimated. Both males and females were recruited, as our 175 previous research indicated no sex related differences in ion reabsorption rates (Amano et 176 al. 2017). Participants were asked to refrain from consuming high sodium foods, caffeine 177 or alcohol and to avoid any strenuous exercise 24 hours preceding the trials. For the 178 experimental trials they were instructed to record their food and beverage intake during the 
179 preceding 24 hours and asked to replicate this for each trial. To promote euhydration, 180 participants were instructed to consume $500 \mathrm{ml}$ of water 1-2 hours prior to the experiments.

181 Upon arrival to the laboratory, participants provided a urine sample and hydration status 182 was checked by a handheld refractometer (Atago Co.Ltd, Tokyo, Japan). All participants 183 met the criteria for adequate hydration (USG <1.025) except two participants both on one 184 occasion each. In these cases the participants were required to consume a further $300 \mathrm{ml}$ 185 prior to the start of the experiments. All participants were non-smokers and were not taking any medications. Menstrual cycle phase per se was not controlled for in the female participants but each female was tested within the same stage of their cycle.

Experimental trials Participants visited the laboratory twice for the manipulation of local forearm $\mathrm{T}_{\mathrm{sk}}$.

191 Each trial was separated by at least 48 hours. All experimental trials were conducted in a 192 climatic chamber (SR-3000; Nagano Science, Osaka, Japan) controlled at $27^{\circ} \mathrm{C}, 50 \%$ 193 relative humidity, with minimal air movement. All tests were completed at the same time 194 of day ( $\pm 1 \mathrm{hr}$ ), at least 2 hours after their last meal. During all experimental trials, 195 participants wore standardized shorts and females also wore a sports bra underneath a water-perfused suit (Allen-Vanguard, Ottawa, Canada) to help elevate the thermal load and in an attempt to maintain a similar $\mathrm{T}_{\mathrm{sk}}$ across the body. oesophageal thermometer, as an index of core temperature $\left(\mathrm{T}_{\mathrm{es}}\right)$, to the distance of one-

201 fourth of standing height from the external nares (Mekjavic and Rempel 1990). After 202 entering the chamber participants donned a water-perfused suit that covered the body 203 except face, forearms, hands and lower legs (from above the knee). Participants then rested 
in a semi supine position for approximately $60 \mathrm{mins}$ whilst the measuring instruments were attached (detailed below) and local $\mathrm{T}_{\mathrm{sk}}$ of the forearm was manipulated and remained stable at the desired local $\mathrm{T}_{\mathrm{sk}}$ (detailed below). During the instrumentation preparation phase, water at $34^{\circ} \mathrm{C}$ was passed through the suit at a flow rate of $750 \mathrm{ml} / \mathrm{min}$ to maintain a stable resting mean $\mathrm{T}_{\mathrm{sk}}$. Following instrumentation, baseline data were recorded for 5 minutes and a salivary aldosterone sample collected. Participants were then heated exogenously for 45 minutes separated into two phases. The first phase involved submerging the lower legs into a water bath set at $42^{\circ} \mathrm{C}$ and increasing the water temperature inside the suit to $40^{\circ} \mathrm{C}$ for 20 minutes. For the remaining 25 minutes, the lower leg water bath temperature was increased to $43^{\circ} \mathrm{C}$ and the temperature of the water inside the suit was increased to $45^{\circ} \mathrm{C}$.

215 (Neutral), whilst the other forearm was either manipulated to elicit a cool $\mathrm{T}_{\mathrm{sk}}$ of $30^{\circ} \mathrm{C}(\mathrm{Cool})$ or a warm temperature of $36^{\circ} \mathrm{C}$ (Warm) in a balanced order. For clarity, in the rest of the 217 document the phrase Neutral-Cool will be used to indicate when one forearm was 218 manipulated to be Neutral and the other Cool, and Neutral-Warm when one forearm was 219 manipulated to be Neutral and the other Warm. Sweat rate on bilateral forearms are comparable (Buono et al. 2011; Kenefick et al. 2012; Smith and Havenith 2012) and thus we assume asymmetry between the left and right arm and use the mean of the two neutral 222 conditions. To manipulate local forearm $\mathrm{T}_{\mathrm{sk}}$, custom-made water perfused patches were 223 wrapped around the left and right ventral forearm during each experiment. The water 224 perfused patches consisted of tubes (inside diameter $=2 \mathrm{~mm}$, outside diameter $=4 \mathrm{~mm}$ ) running in a circular motion with no gaps between tubes. A small hole positioned in the centre of the patch allowed for entrance and exit of the sweat capsule tubes. Both patches

227 were of equal surface area $(16 \times 13 \mathrm{~cm})$ and water was supplied to each patch at a flow rate 228 of $250 \mathrm{ml} / \mathrm{min}$ (Variable-flow Chemical Transfer Pump, Fisher Scientific ${ }^{\mathrm{TM}}$ ). The patches 
were connected to two separate water baths (Taitec Therminder DX-10 and SP12, Taitec

230 Corporation, Saitama, Japan) where the water temperature was altered to achieve the

231 desired local $\mathrm{T}_{\text {sk. }}$. The water temperature used varied for each participant but was 232 approximately $29.4 \pm 3.2^{\circ} \mathrm{C}$ for Neutral, $15.8 \pm 5.8^{\circ} \mathrm{C}$ for $\mathrm{Cool}$ and $40.2 \pm 2.2^{\circ} \mathrm{C}$ for Warm

233 conditions. To control the cold-water temperature an immersion cooler (Taitec Cool pipe 234 300LF, Taitec Corporation, Saitama, Japan) was used concomitantly with the water bath. The water patches were positioned onto the forearms for a minimum of 30 minutes prior to the start of the test, whereby local $\mathrm{T}_{\mathrm{sk}}$ was altered until the desired temperatures were reached. Local $\mathrm{T}_{\mathrm{sk}}$ was maintained at the desired temperature for a minimum of 5 minutes prior to the start of the experiment. If the local $\mathrm{T}_{\mathrm{sk}}$ of the forearms during passive heating increased or decreased by more than $1{ }^{\circ} \mathrm{C}$ of the target local $\mathrm{T}_{\mathrm{sk}}$, the temperature of the water bath was altered.

During the final minute of each experiment, a salivary aldosterone sample was collected. This was then followed by the removal of the forearm skin patches and all 243 instruments so that the number of heat-activated sweat glands (HASG) using the starch244 iodine technique (Inoue 1996) could be measured. Once these samples were collected the passive heating protocol was completed.

\section{Measurements}

For the determination of mean skin temperature (mean $\left.\mathrm{T}_{\mathrm{sk}}\right), 4$ sites (chest, forearm, 249 thigh and calf) were measured. In addition, local $\mathrm{T}_{\text {sk }}$ underneath the skin patch at the left and right forearm was measured at two locations adjacent to the sweat capsule and averaged. Both $\mathrm{T}_{\mathrm{es}}$ and $\mathrm{T}_{\mathrm{sk}}$ were measured using copper-constantan thermocouples (Inui

252 Engineering, Higashi Osaka, Japan). The tip of the oesophageal thermometer was covered 253 with silicon and the skin thermocouples were uncovered and attached to the skin using 
254 Medipore tape. Mean $T_{\text {sk }}$ and mean body temperature $\left(T_{b}\right)$ were calculated using the 255 following respective formula (Stolwijk and Hardy 1966; Gagge and Nishi 2011);

$$
\mathrm{T}_{\mathrm{b}}=\left(0.8 \times \mathrm{T}_{\mathrm{es}}\right)+\left(0.2 \times \text { mean } \mathrm{T}_{\mathrm{sk}}\right)
$$

$$
\text { Mean } \mathrm{T}_{\mathrm{sk}}=(\text { chest } \times 0.34)+(\text { calf } \times 0.18)+(\text { thigh } \times 0.33)+(\text { forearm } \times 0.15)
$$

258 For the calculation of mean $\mathrm{T}_{\mathrm{sk}}$ the forearm $\mathrm{T}_{\mathrm{sk}}$, was based on the average of both the left 259 and right forearm $\mathrm{T}_{\text {sk. }}$

SR was measured using the ventilated capsule method on the right and left mid-

261 ventral forearm. Dry nitrogen gas was flushed $(500 \mathrm{ml} / \mathrm{min})$ through the apparatus 262 approximately 1 hour prior to each experiment to ensure stable readings. Each capsule (3.14 $263 \mathrm{~cm}^{2}$ ) was affixed to the skin using double-sided tape at least 30 minutes prior to data 264 collection. The temperature and humidity of the air flowing out of the capsule was 265 measured using a capacitance hygrometer (HMP50; Vaisala, Helsinki, Finland). Two $\mathrm{Ag} / \mathrm{AgCl}$ electrodes (Vitrode J, Nihon Kohden, Tokyo, Japan) for measuring GSC were 267 attached either side of the sweat capsules, approximately $3 \mathrm{~cm}$ apart (MP100 and GSC100C;

268 Biopac, Goleta CA, USA). GSC is expressed as a change from baseline ( $\triangle \mathrm{GSC})$, recorded 269 during the 5 minute resting phase prior to heating. Cutaneous vascular conductance (CVC) 270 was estimated by measuring skin blood flow on each forearm using laser-Doppler 271 velocimetry (ALF21; Advanced, Tokyo, Japan). CVC was calculated as a percentage of 272 the baseline value recorded during the resting phase prior to heating. $\mathrm{T}_{\mathrm{es}}$, local $\mathrm{T}_{\mathrm{sk}}, \mathrm{SkBf}$, 273 SR and GSC were recorded every second by a data logger (MX100; Yokogawa, Tokyo, 274 Japan) and 1 min averaged calculated. Heart rate and arterial blood pressure were 275 continuously measured on the left middle finger using a Finometer (Finometer; Finapres 276 Medical Systems, Amsterdam, The Netherlands); mean arterial pressure (MAP) was 277 subsequently calculated and averaged over 5-min periods. 
held in place over the measurement area for approximately $3 \mathrm{sec}$. The iodine was transferred from the HASG to the paper as indicated by a small dot. The same investigator counted the dots within a defined area $\left(1 \mathrm{~cm}^{2}\right)$. The sweat gland output per gland (SGO) at the respective site was calculated by dividing the SR (averaged from the last 5 minutes of the experiment) by the number of HASG.

Salivary and urine aldosterone was collected using Salivettes ${ }^{\mathrm{TM}}$ (Sarstedt, Newton, NC, USA) whereby a plain cotton swab was inserted into the mouth and chewed for $60 \mathrm{sec}$. The cotton swab was then returned into the Salivette ${ }^{\mathrm{TM}}$ tube and spun at 4000RPM for 10 minutes. Samples were then frozen at $-30^{\circ} \mathrm{C}$ until analysis. After thawing, salivary aldosterone (pg/ml) levels were quantified by competitive ELISA (LDN, GmbH \& Co.KG, 292 Germany). The sensitivity of the assay for aldosterone was $14 \mathrm{pg} / \mathrm{ml}$ and the inter- and intraassay coefficient of variation were between $3.9-7.5 \%$ and $9.4-9.7 \%$, respectively.

Data analysis

As described in our previous experiments (Amano et al. 2016, 2017; Gerrett et al. 2018a), the maximum reabsorption rate of the sweat glands was obtained by plotting $\Delta \mathrm{GSC}$ against $\Delta \mathrm{SR}$. By plotting this relationship, it is possible to identify three distinct phases; representing different stages of sweat production. In the first phase, there is an increase in $\Delta \mathrm{GSC}$ but no change in $\Delta \mathrm{SR}$, which represents the isosmotic precursor sweat production in the proximal secretory coil. Such changes in $\Delta \mathrm{GSC}$ and no changes in $\Delta \mathrm{SR}$ are frequently 
$\Delta \mathrm{SR}$ without an increase in $\Delta \mathrm{GSC}$ can be observed. As $\Delta \mathrm{GSC}$ is influenced by both the amount of sweat produced as well as the electrolyte concentration the fact that $\Delta \mathrm{SR}$ increases but there is no change in $\triangle \mathrm{GSC}$ represents reabsorption of sweated ions in the sweat duct. Once the rate of sweat ion secretion exceeds its reabsorption limit in the duct then the third phase occurs where there is a proportional increase in $\Delta \mathrm{GSC}$ with increasing $\Delta \mathrm{SR}$. The point at which the $2^{\text {nd }}$ and $3^{\text {rd }}$ phase intersect is used to identify the maximum rate of sweat glands ion reabsorption. In the present study, the thresholds were determined using segmented regression analysis on GraphPad Prism (version 7) software.

To investigate the effect of local $\mathrm{T}_{\mathrm{sk}}$ on local maximum ion reabsorption, local $\mathrm{SR}$, local $\triangle \mathrm{GSC}$ and local CVC, a one-way repeated measure ANOVA with condition (Warm, Neutral and Cool) was carried out. The relation between temperature and ion reabsorption rates were analysed with correlation analysis; using normalized data to reduced individual effects. Correlation coefficients were considered as strong $(\geq 0.60)$, moderate $(0.40-0.59)$, and weak (0.20-0.39) (Cohen 1977).

A two-way ANOVA was used to assess the remaining thermophysiological parameters $\left(\mathrm{T}_{\mathrm{es}}, \mathrm{T}_{\mathrm{b}}\right.$ and mean and local $\left.\mathrm{T}_{\mathrm{sk}}\right)$ and cardiovascular responses $(\mathrm{CVC}$, a one-way repeated measure ANOVA) to determine any differences between conditions (Neutral-

321 Cool vs. Neutral-Warm) and over time. When any significant effects were observed, post 322 hoc comparison using the Bonferroni test were carried out. All data were checked for 323 sphericity and normality (Shapiro-Wilk test). As ANOVA's are fairly robust to violations 324 of normality, if the data were approximately normal then the data was assessed with 325 parametric data analysis. If the data violated this assumption substantially then a 326 Friedman's test was performed (comparing Neutral, Cool and Warm data); this was the 327 case for the following sets of data: local forearm, chest and thigh $\mathrm{T}_{\mathrm{sk}}$ and SR. All data were 
analysed using GraphPad Prism (version 7). Effect sizes (Cohen's d) were calculated for the local maximum ion reabsorption rates with the following criteria; an effect size of $<0.20$ is classified as 'trivial', $0.21-0.49$ as 'small', $0.50-079$ as 'moderate' and $>0.80$ as a 'large' effect. Values are means and standard deviations $( \pm \mathrm{SD})$ and statistical significance was set at $\mathrm{p}<0.05$.

\section{Results}

\section{Local skin temperature}

336 The local forearms $\mathrm{T}_{\mathrm{sk}}$ are illustrated in Figure 1. Forearm $\mathrm{T}_{\mathrm{sk}}$ during Warm $\left(36.4 \pm 0.4^{\circ} \mathrm{C}\right)$ 337 were higher $(\mathrm{p}<0.05)$ than Neutral $\left(33.5 \pm 0.7^{\circ} \mathrm{C}\right)$ and the $\mathrm{Cool}\left(30.5 \pm 1.0^{\circ} \mathrm{C}\right)$ conditions $338(\mathrm{p}<0.05)$. The latter was also lower than both the Neutral conditions $(\mathrm{p}<0.05)$. The local $\mathrm{T}_{\text {sk }}$ on the Neutral arm was not affected by the temperature on the experimental arm (NeutralCool; $33.6 \pm 0.7^{\circ} \mathrm{C}$ and Neutral-Warm; $\left.33.7 \pm 0.7^{\circ} \mathrm{C}, \mathrm{p}>0.05\right)$. Forearm $\mathrm{T}_{\text {sk }}$ increased over

341 time in all conditions $(\mathrm{p}<0.05)$ and was significantly higher than baseline after 40,25 and

34230 mins until the end of the experiment for Warm, both Neutral and Cool conditions, 343 respectively. The increases from baseline to the end of passive heating were however similar between conditions (Warm; $+0.9 \pm 0.4^{\circ} \mathrm{C}$, Neutral $+1.2 \pm 0.5^{\circ} \mathrm{C}, \mathrm{Cool} ;+1.7 \pm 0.8^{\circ} \mathrm{C}$, no interaction effect, $\mathrm{p}>0.05$ ).

\section{Maximum ion reabsorption}

348 The maximum ion reabsorption thresholds, as indicated by the $\Delta \mathrm{SR}$ threshold for an increasing $\triangle \mathrm{GSC}$, are illustrated in Figure 2. There is a significant pattern for a temperature dependent response for maximum ion reabsorption threshold (Warm; $0.28 \pm$ $0.14 \mathrm{mg} / \mathrm{cm}^{2} / \mathrm{min}$, Neutral; $0.22 \pm 0.12 \mathrm{mg} / \mathrm{cm}^{2} / \mathrm{min}$, Cool; $0.18 \pm 0.10 \mathrm{mg} / \mathrm{cm}^{2 /} \mathrm{min}$, $352 \mathrm{p}<0.05)$, with differences noted between Warm and Cool only $(d=0.88, \mathrm{p}=0.024)$. There 
were small effect sizes for the maximum ion reabsorptions between Neutral and Warm $(d$ $354=0.44, \mathrm{p}>0.05)$ and Neutral and Cool $(d=0.36, \mathrm{p}>0.05)$. A weak, significant relation exits 355 between local $T_{\text {sk }}$ and the $\Delta S R$ threshold for maximum ion reabsorption $\left(r^{2}=0.36, p<0.05\right)$

Thermo-physiological measurements

$\mathrm{T}_{\mathrm{es}}, \mathrm{T}_{\mathrm{b}}$ and mean $\mathrm{T}_{\mathrm{sk}}$ are illustrated in Figure $3 \mathrm{~A}-\mathrm{C} . \mathrm{T}_{\mathrm{es}}$ were similar between conditions (Neutral-Warm; $37.1 \pm 0.3^{\circ} \mathrm{C}$ and Neutral-Cool $37.2 \pm 0.3^{\circ} \mathrm{C}, \mathrm{p}>0.05$ ) and both gradually increased over time $(\mathrm{p}<0.05)$, although the increase was similar between conditions ( $\Delta$ Tes: Neutral-Warm; $0.92 \pm 0.2^{\circ} \mathrm{C}$ and Neutral-Cool $\left.0.77 \pm 0.1^{\circ} \mathrm{C} \mathrm{p}>0.05\right) . \mathrm{T}_{\mathrm{b}}$ were similar between conditions (Neutral-Warm; $36.9 \pm 0.3^{\circ} \mathrm{C}$ and Neutral-Cool $36.8 \pm$ $\left.0.3^{\circ} \mathrm{C}, \mathrm{p}>0.05\right)$ and both gradually increased over time $(\mathrm{p}<0.05)$, although the increases were similar between conditions ( $\Delta$ Tes: Neutral-Warm; $1.4 \pm 0.03^{\circ} \mathrm{C}$ and Neutral-Cool 1.3 $\left.\pm 0.02^{\circ} \mathrm{C} \mathrm{p}>0.05\right)$.

Cool $\left(34.9 \pm 1.0^{\circ} \mathrm{C}\right)$ conditions $(\mathrm{p}<0.05)$ and did increase over time $(\mathrm{p}<0.05)$, although the 368 increase was similar between conditions ( $\Delta$ mean $\mathrm{T}_{\mathrm{sk}}$ : Neutral-Warm; $3.3 \pm 0.5^{\circ} \mathrm{C}$ and 369 Neutral-Cool $3.2 \pm 0.3^{\circ} \mathrm{C}$; no interaction effect, $\mathrm{p}>0.05$ ). Local $\mathrm{T}_{\mathrm{sk}}$ of the chest, thigh and calf were similar between conditions (Neutral-Warm; $35.4 \pm 5.6^{\circ} \mathrm{C}, 33.4 \pm 5.2^{\circ} \mathrm{C}, 42.0 \pm$ 7.0 ${ }^{\circ} \mathrm{C}$ and Neutral-Cool: $35.3 \pm 5.5^{\circ} \mathrm{C}, 33.2 \pm 5.3^{\circ} \mathrm{C}, 41.9 \pm 7.0^{\circ} \mathrm{C}, \mathrm{p}<0.05$, respectively).

372 They all increased over time $(\mathrm{p}<0.05)$ although the increase was similar between conditions 373 (no interaction effect, $\mathrm{p}>0.05$ ).

SR and $\triangle \mathrm{GSC}$ measured at the forearms whilst local forearm $\mathrm{T}_{\mathrm{sk}}$ were maintained at a Warm $\left(36^{\circ} \mathrm{C}\right)$, Neutral $\left(33^{\circ} \mathrm{C}\right)$ or $\mathrm{Cool}\left(30^{\circ} \mathrm{C}\right)$ temperatures are illustrated in Figure 4. 
378 SR was higher during both Warm $\left(0.43 \pm 0.26 \mathrm{mg} / \mathrm{cm}^{2} / \mathrm{min}\right)$ and the Neutral conditions 379 (Neutral-Warm; $0.40 \pm 0.3 \mathrm{mg} / \mathrm{cm}^{2} / \mathrm{min}$, and Neutral-Cool $0.40 \pm 0.2 \mathrm{mg} / \mathrm{cm}^{2} / \mathrm{min}$ ) than 380 Cool $\left(0.35 \pm 0.2 \mathrm{mg} / \mathrm{cm}^{2} / \mathrm{min}\right)$. SR increased over time in all conditions $(\mathrm{p}<0.05)$ and was 381 significantly higher than baseline from 30 mins until the end of passive heating. The 382 increases from baseline to the end of passive heating were similar between conditions 383 (Warm; $+0.62 \pm 0.24 \mathrm{mg} / \mathrm{cm}^{2} / \mathrm{min}$, Neutral $+0.61 \pm 0.23 \mathrm{mg} / \mathrm{cm}^{2} / \mathrm{min}$, Cool; $+0.54 \pm 0.15$ 384 $\mathrm{mg} / \mathrm{cm}^{2} / \mathrm{min}$, no interaction effect, $\left.\mathrm{p}>0.05\right)$.

$\Delta \mathrm{GSC}$ was not significantly different between Warm $(10.3 \pm 11.5 \mu \mathrm{S})$, Neutral $(10.1$ $\pm 9.8 \mu \mathrm{S})$, or $\mathrm{Cool}(8.6 \pm 11.3 \mu \mathrm{S})$ conditions $(\mathrm{p}>0.05) . \Delta \mathrm{GSC}$ increased from baseline after 10 mins for all conditions $(\mathrm{p}<0.05)$. There was no interaction effect as the increases from baseline to the end of passive heating were similar between conditions (Warm; $18.1 \pm 14.6$ $\mu \mathrm{S}$, Neutral; $19.4 \pm 12.8 \mu \mathrm{S}, \mathrm{Cool} ; 19.35 \pm 14.1 \mu \mathrm{S}, \mathrm{p}>0.05)$

The HASG was similar between conditions: Warm; $107 \pm 20$ gland $/ \mathrm{cm}^{2}$, Neutral; $120 \pm 24$ gland $/ \mathrm{cm}^{2}$, Cool; $115 \pm 18$ gland $/ \mathrm{cm}^{2}(\mathrm{p}>0.05)$. The SGO was similar between conditions: Warm; $6.9 \pm 2.7 \mu \mathrm{g} / \mathrm{gland} / \mathrm{min}$, Neutral; $5.6 \pm 1.7 \mu \mathrm{g} / \mathrm{gland} / \mathrm{min}$, Cool; $5.3 \pm 1.1$ $\mu \mathrm{g} / \mathrm{gland} / \mathrm{min}, \mathrm{p}>0.05)$.

The $\mathrm{T}_{\mathrm{es}}$ threshold for $\mathrm{SR}$ was not significantly different between conditions (Warm; not significantly different (Warm; $0.74 \pm 0.4$, Neutral; $1.00 \pm 0.3$, Cool; $1.13 \pm 0.5, \mathrm{p}>0.05$ ).

\section{Urine and Salivary Aldosterone}

Urine aldosterone concentrations were similar between conditions (Neutral-Warm; 
time (pre vs. post); there was also no interaction effect (Neutral-Warm-pre; $122.2 \pm 40.5$ pg/ml, Neutral-Warm-post; $116.1 \pm 43.0$ pg/ml, and Neutral-Cool-pre; $113.7 \pm 28.9 \mathrm{pg} / \mathrm{ml}$ and Neutral-Cool post; $115.8 \pm 41.7 \mathrm{pg} / \mathrm{ml}, \mathrm{p}>0.05)$.

\section{Cardiovascular measurements}

HR, MAP, CVC are presented in Table 1. HR's were similar between conditions

(Neutral-Warm; $78.0 \pm 8$ bpm and Neutral-Cool $79.0 \pm 9$ bpm, $\mathrm{p}>0.05$ ) and both gradually increased over time $(\mathrm{p}<0.05)$ and the increase was similar between conditions $(\Delta \mathrm{HR}$ :

411 Neutral-Warm; $30.0 \pm 2 \mathrm{bpm}$ and Neutral-Cool $31.2 \pm 2 . \mathrm{bpm}, \mathrm{p}>0.05)$. MAP were similar 412 between conditions (Neutral-Warm; $99.2 \pm 2 \mathrm{mmHg}$ and Neutral-Cool $99.1 \pm 2 \mathrm{mmHg}$, $413 \mathrm{p}>0.05)$ and did not increase over time in either condition $(\mathrm{p}>0.05)$.

\section{Discussion}

The aim of the present study was to investigate the influence of local $\mathrm{T}_{\mathrm{sk}}$ on the 417 eccrine sweat glands maximum ion reabsorption rates during passive heating. We 418 hypothesised that the sweat glands maximum ion reabsorption rates would occur at a higher 419 sweat rate $(\mathrm{SR})$ with a higher local $\mathrm{T}_{\text {sk }}\left(36^{\circ} \mathrm{C}\right)$ compared to neutral $\left(33^{\circ} \mathrm{C}\right)$ and cool $\mathrm{T}_{\text {sk }}$ $420\left(30^{\circ} \mathrm{C}\right)$. The data indicates that there is a temperature dependent response, which was most 421 prominent when local $\mathrm{T}_{\mathrm{sk}}$ differed by $6^{\circ} \mathrm{C}\left(30^{\circ} \mathrm{C}\right.$ vs. $\left.36^{\circ} \mathrm{C}\right)$ whilst not when local $\mathrm{T}_{\mathrm{sk}}$ differed 422 by only $3^{\circ} \mathrm{C}\left(30^{\circ} \mathrm{C}\right.$ vs. $33^{\circ} \mathrm{C}$ and $33^{\circ} \mathrm{C}$ vs. $\left.36^{\circ} \mathrm{C}\right)$. In practical terms, a higher $\Delta \mathrm{SR}$ for 423 maximum ion reabsorption means that a more dilute sweat would be secreted onto the skin surface for a given SR, which may be advantageous when sweat rate is high to prevent the excess loss of ions. By selecting a passive heating protocol, we ensured that the values were

426 obtained in controlled conditions to eliminate any potential effect from non-thermal control 427 mechanisms, such as aldosterone, and other potential thermal controllers such as core and 
428 body temperature. Mean $\mathrm{T}_{\mathrm{sk}}$ was significantly different by only approximately $0.6^{\circ} \mathrm{C}$ 429 between conditions, which is likely due to differences in local $\mathrm{T}_{\text {sk }}$ manipulations as all other 430 measured local skin site temperatures were similar between conditions.

\section{Thermal mechanism}

We hypothesized that the maximum sweat gland ion reabsorption rate would be 434 affected by local $\mathrm{T}_{\mathrm{sk}}$ as previous studies, in vivo and in vitro, have reported a temperature 435 dependency of $\mathrm{Na}^{+}$channels excitability and ion reabsorption regulation (Ruff 1999; 436 Chraïbi and Horisberger 2003; Shamsuddin et al. 2005a). The reabsorption of $\mathrm{NaCl}$ is 437 primarily driven by the movement of $\mathrm{Na}^{+}$down a steep concentration gradient that is 438 generated by the $\mathrm{Na}^{+} / \mathrm{K}^{+}$pump via $\mathrm{ENaC}$ (Bovell 2015). In vitro studies utilising a wide 439 temperature range $\left(19^{\circ} \mathrm{C}\right.$ and $\left.37^{\circ} \mathrm{C}\right)$ have demonstrated the temperature dependency of $\mathrm{Na}^{+}$ 440 channels excitability; where $30 \%$ and $93 \%$ of the channels were excitable at these

441 respective temperatures (Ruff 1999). However, the percentages of excitable channels 442 became less prominent when comparing $31^{\circ} \mathrm{C}$ and $37^{\circ} \mathrm{C}(85 \%$ vs. $93 \%$, respectively), which 443 are closer to the physiological temperatures experienced whilst sweating. Chraïbi and 444 Horisberger (2003) more recently showed that ENaC open probability was greater at lower $445\left(15^{\circ} \mathrm{C}\right)$ compared to higher temperatures $\left(24-30^{\circ} \mathrm{C}\right)$. Indeed other studies showing 446 temperature dependency of $\mathrm{ENaC}$, and cystic fibrosis transmembrane channels (CFTR) that 447 are responsible for the reabsorption of $\mathrm{Cl}^{-}$and interacts with $\mathrm{ENaC}$ (Reddy and Quinton 448 2003), show the effects of temperature are more prominent outside the physiological ranges 449 examined in the present study. Our data indicates that when $\mathrm{T}_{\mathrm{sk}}$ is within appropriate 450 physiological ranges of $30-33-36^{\circ} \mathrm{C}$, a $\mathrm{T}_{\text {sk }}$ difference of $\sim 3^{\circ} \mathrm{C}$ is an insufficient temperature 451 stimulus to affect the maximum rate of ion reabsorption but differences of $\sim 6^{\circ} \mathrm{C}$ may elicit 452 changes of approximately $0.1 \mathrm{mg} / \mathrm{cm}^{2} / \mathrm{min}$. Whilst the inter and intra-individual variability 
is high for sweating responses, the ventilated sweat capsule technique is highly reliable and accurate and thus we are confident that our method is sensitive to detect these differences. Whilst GSC is more variable, the values themselves are less meaningful but the pattern of the response in relation to SR is important for detecting the sweat glands ion reabsorption 457 rates.

Contrasting to our findings, Shamsuddin et al. (2005a) reported differences in ion reabsorption rates when mean $\mathrm{T}_{\mathrm{sk}}$ was clamped at $\sim 31^{\circ} \mathrm{C}$ and $\sim 28^{\circ} \mathrm{C}$, a differences of $3^{\circ} \mathrm{C}$, during dynamic exercise. These findings, alongside the in vitro studies mentioned earlier may indicate that cooler temperatures $\left(<30^{\circ} \mathrm{C}\right)$ have stronger effects on ion regulation.

462 Alternatively, smaller differences in $\mathrm{T}_{\text {sk }}$ may affect ion reabsorption rates during dynamic 463 exercise when hormonal mediators are likely in effect. et al. (2005a) were not significantly different between the two conditions; thereby eliminating the role of $T_{\text {es }}$ as a controlling mechanism. However, that is not to say that $T_{c}$

467 per se will not influence the sweat glands maximum ion reabsorption rates in other 468 conditions outside the realms of the studies under discussion. Temperature stimulation has 469 been deemed an important regulatory mechanism for sudomotor activity. We reported no 470 significant differences between conditions in the $T_{\text {es }}$ threshold for the onset of neither 471 sweating, nor the slope, or the SGO in this study. Indeed, the relative importance of $\mathrm{T}_{\mathrm{c}}$ on

472 SR compared to mean $\mathrm{T}_{\mathrm{sk}}$ is well known (Nadel et al. 1971) and both $\mathrm{Na}^{+}$secretion and $473 \mathrm{Na}^{+}$reabsorption increase linearly with increasing SR (Buono et al. 2008). As SR increases 474 it has been suggested that there becomes insufficient time for sweat ion reabsorption to 475 occur and hence a maximum reabsorption rate is reached. The SR for maximum ion 476 reabsorption occurred between 0.18 and $0.28 \mathrm{mg} / \mathrm{cm}^{2} / \mathrm{min}$ across the 3 temperature ranges, 
477

478

479

480

481

482

483

484

485

486

487

488

489

490

491

492

493

494

495

496

497

498

499

500

501

which typically occurred within 15 minutes of passive heating. As can be seen in left panel of Figure 4, the SR response over time is similar between conditions, as also confirmed by a non-significant interaction effect (condition $\mathrm{x}$ time). It seems therefore that if any thermal controls exist over the sweat glands maximum ion reabsorption rates, it requires a stronger thermal input (e.g. from mean $\mathrm{T}_{\mathrm{sk}}$ and/or $\mathrm{T}_{\mathrm{c}}$ ) than from small changes $\left(\leq 3^{\circ} \mathrm{C}\right)$ in local $\mathrm{T}_{\mathrm{sk}}$. It would be interesting to determine the minimum change in local $\mathrm{T}_{\mathrm{sk}}$ that would affect the sweat glands maximum ion reabsorption rate. The role of $\mathrm{T}_{\mathrm{c}}$ on $\mathrm{SR}$ and ion reabsorption seems likely, but certainly warrants clarification, as to does the role of mean and local $\mathrm{T}_{\mathrm{sk}}$ under varying $\mathrm{T}_{\mathrm{c}}$ responses.

Previous studies have reported higher reabsorption rates on the torso compared to the extremities but have been unable to determine any contributing mechanism as regional differences in local $\mathrm{T}_{\mathrm{sk}}$ existed (Inoue et al. 1998; Amano et al. 2017). The findings of the present study provide important information to help elucidate why these regional differences occur and variations in local $\mathrm{T}_{\mathrm{sk}}$ can be ruled out, as regional differences were less than $\sim 2^{\circ} \mathrm{C}$. Instead, we hypothesize that structural differences in the sweat glands across the body may account for the regional differences reported in aforementioned studies.

\section{Non-thermal mechanism}

Regulation of ion loss is predominated in the literature by renal function despite potential large fluid and ion losses from eccrine sweat glands during exercise and/or heat exposure. Although structurally and functionally different to the kidneys, the influence of various water regulating hormones (arginine vasopressin, aldosterone and atrial natriuretic peptide) on sweat output have been investigated (Kirby and Convertino 1986; Hew-Butler et al. 2010, 2014). The precise mechanism for the regulation of the ion reabsorption is unknown but it is hypothesized that aldosterone, an important hormone in renal sodium 
regulation, plays a role. Acting on mineralocorticoid receptors, aldosterone increases 503 intracellular calcium, which regulates epithelial $\mathrm{Na}^{+}$and $\mathrm{K}^{+}$channels, reportedly by 504 increasing either the permeability of the membrane to $\mathrm{Na}^{+}$, increasing active transport of $505 \mathrm{Na}^{+}$out of the cell and/or increasing the energy available to the $\mathrm{Na}^{+} / \mathrm{K}^{+}$pump (Hegarty and 506 Harvey 1998; Harvey and Higgins 2000).

507 By using a passive heating protocol, our study aimed to reduce non-thermal 508 mediators, such as water-regulatory hormones (e.g. aldosterone, vasopressin and plasma renin activity) that are released during exercise (Convertino et al. 1983; Freund et al. 1991;

510 Yoshida et al. 2006). We confirmed similar aldosterone concentrations between our two 511 conditions, both before and after passive heating. In addition, hydration statuses were 512 similar between both conditions so to rule out any potential effects of hydration on 513 circulating hormones. Previous research by Shamsuddin et al. (2005a) reported a role of 514 mean $\mathrm{T}_{\text {sk }}$ on ion reabsorption, but this occurred during dynamic exercise (cycling at $60 \%$ $\left.515 \dot{V} \mathrm{O}_{2 \max }\right)$ where aldosterone concentrations would have been elevated, as demonstrated in our previous research comparing passive heating and cycling at $60 \% \dot{V} \mathrm{O}_{2 \max }($ Gerrett et al.

517 2018a). Shamsuddin et al. (2005a), speculated that higher $\mathrm{T}_{\mathrm{sk}}$ might enhance the 518 responsiveness of the sweat glands to a given aldosterone concentration. In the present 519 study however, aldosterone concentrations remained unchanged but local $\mathrm{T}_{\text {sk }}$ differed and 520 we hypothesize that small differences $\left(\leq 3^{\circ} \mathrm{C}\right)$ in $\mathrm{T}_{\mathrm{sk}}$ may only affect ion reabsorption rates 521 when aldosterone (or other water regulatory hormones) are elevated. Further support is 522 provided from our previous research where higher maximum ion reabsorption rates were 523 reported during moderate intensity exercise (supine cycling at $60 \% \dot{V} \mathrm{O}_{2 \max }$ ) compared to 524 passive heating (lower leg submersion $43^{\circ} \mathrm{C}$ water), despite a lower mean $\mathrm{T}_{\text {sk. }}$ We attributed 525 those differences partially to the elevated salivary aldosterone concentrations during 526 exercise compared to passive heating. To date no studies have determined the effect of 
527 varying $\mathrm{T}_{\mathrm{sk}}$ and/or $\mathrm{T}_{\mathrm{c}}$ on aldosterone concentrations during exercise but it certainly warrants 528 investigation.

529 Perspective

530 Sodium chloride plays an important role in the formation of sweat within the 531 secretory coil. Why we do not, or cannot, reabsorb all the sodium chloride ions in the 532 reabsorptive duct is not clear; it may play a role in the evaporative potential of sweat on the 533 skin surface, it may aid skin barrier function and protection. Yet there is an adaptive 534 response as seen with heat acclimation (Buono et al. 2008; Amano et al. 2016). We know

535 from cases of cystic fibrosis that preventing an excess loss of these ions is an important 536 regulatory mechanism yet, it is poorly understood and often overlooked in favour of its 537 thermoregulatory role. The regulation of ion reabsorption is a fundamental research 538 question that requires further consideration.

Furthermore, in recent years there has been a drive to produce non-invasive

540 techniques to inform us about the human condition, using sweat as the medium. As a result, 541 the development of sensors to continuously measure sweat content is a rapidly growing 542 field in biomedical engineering but our knowledge of sweat ion regulation is limited and 543 this fundamental study adds to our knowledge. We provide further insight into the 544 methodological considerations for future studies in this area. In particular, our research 545 group has been accumulating consistent evidence of regional differences in ion 546 reabsorption across the body and the current study suggest these regional differences may 547 not have been due to differences in $\mathrm{T}_{\text {sk }}$ but rather structural or regulatory differences at the 548 level of the sweat gland across the body. If $\mathrm{T}_{\text {sk }}$ is expected to vary considerably then 549 knowing the $\mathrm{T}_{\mathrm{sk}}$ is important. Consistent sensor placement in the same locations will allow 550 for better comparisons between conditions and from different studies. 


\section{Conclusion}

Local $\mathrm{T}_{\text {sk }}$ within physiological ranges of $30-33-36^{\circ} \mathrm{C}$ only influenced the sweat

553 glands maximum ion reabsorption rates during a passive heating protocol when local $\mathrm{T}_{\mathrm{sk}}$ 554 differed by $6^{\circ} \mathrm{C}\left(30^{\circ} \mathrm{C}\right.$ vs. $\left.36^{\circ} \mathrm{C}\right)$, whilst no differences were observed when local $\mathrm{T}_{\text {sk }}$ 555 differed by $3^{\circ} \mathrm{C}\left(30^{\circ} \mathrm{C}\right.$ vs. $33^{\circ} \mathrm{C}$ and $33^{\circ} \mathrm{C}$ vs. $\left.36^{\circ} \mathrm{C}\right)$. These findings were observed when all 556 other potential thermal and non-thermal controlling mechanisms were similar between 557 conditions. Information from the literature and data from our study indicate that thermal 558 controllers may exist but most probably from stronger thermal stimulus, such as mean $\mathrm{T}_{\mathrm{sk}}$ 559 and/or $\mathrm{T}_{\mathrm{c}}$, compared to smaller changes $\left(\leq 3^{\circ} \mathrm{C}\right)$ in local $\mathrm{T}_{\text {sk. }}$. We provide important insights

560 for previous studies that have reported regional differences in maximum ion reabsorption 561 rates but have been unable to confirm such differences in the presence of differing local $562 \mathrm{~T}_{\mathrm{sk}}$. The data provides useful information for furthering our understanding of sweat gland 563 ion reabsorption and potential controlling mechanisms. The application of which may be 564 useful in the fields of thermoregulation, hypo/hypernatremia, dermatology and biosensor 565 technology research.

\section{References}

568 Amano T, Gerrett N, Inoue Y, et al (2016) Determination of the maximum rate of eccrine 569 sweat glands' ion reabsorption using the galvanic skin conductance to local sweat $570 \quad$ rate relationship. Eur J Appl Physiol 116:281-290

571 Amano T, Hirose M, Konishi K, et al (2017) Maximum rate of sweat ions reabsorption during exercise with regional differences, sex, and exercise training. Eur J Appl Physiol 117:. doi: 10.1007/s00421-017-3619-8

574 Bovell D (2015) The human eccrine sweat gland: Structure, function and disorders. J 
576 Bulmer MG, Forwell GD (1956) The concentration of sodium in thermal sweat. J Physiol $32: 5-122$

578 Buono MJ, Claros R, Deboer T, Wong J (2008) Na+ secretion rate increases proportionally more than the $\mathrm{Na}+$ reabsorption rate with increases in sweat rate. $\mathrm{J}$ Appl Physiol 105:1044-1048. doi: 10.1152/japplphysiol.90503.2008.

581 Buono MJ, Jechort A, Marques R, et al (2007) Comparison of infrared versus contact 582 thermometry for measuring skin temperature during exercise in the heat. Physiol Meas 28:855-859. doi: 10.1088/0967-3334/28/8/008

584 Buono MJ, Tabor B, White A (2011) Localized $\beta$-adrenergic receptor blockade does not affect sweating during exercise. Am J Physiol Integr Comp Physiol 300:R1148R1151. doi: 10.1152/ajpregu.00228.2010

Chraïbi A, Horisberger J-D (2003) Dual effect of temperature on the human epithelial Na 588 + channel. Pflugers Arch -Eur J Physiol 447:316-320. doi: 10.1007/s00424-003-

590 Cohen J (1977) Statistical Power Analysis for the Behavioral Sciences. Lawrence

$591 \quad$ Erlbaum Associates, Hillsdale, New Jersey

592 Convertino V a, Keil LC, Greenleaf JE (1983) Plasma volume, renin, and vasopressin 593 responses to graded exercise after training. J Appl Physiol 54:508-514

594 Darrow CW (1964) The rationale for treating the change in galvanic skin response as a $595 \quad$ change in conductance. Psychophysiology 1:31-38

596 Freund BJ, Shizuru EM, Hashiro GM, et al (1991) Hormonal, electrolyte, and renal 597 responses to exercise are intensity dependent. J Appl Physiol 70:900-906

598 Gagge AP, Nishi Y (2011) Heat exchange between human skin surface and thermal 599 environment. In: Comprehensive Physiology. John Wiley \& Sons, Inc., Hoboken, $600 \quad$ NJ, USA, pp 69-92 
601 Gao W, Brooks GA, Klonoff DC (2018) Wearable physiological systems and

602 technologies for metabolic monitoring. J Appl Physiol 1:548-556

603 Gerrett N, Amano T, Inoue Y, et al (2018a) The effects of exercise and passive heating on

604 the sweat glands ion reabsorption rates. Physiol Rep 6:. doi: 10.14814/phy2.13619

605 Gerrett NM, Griggs KE, Redortier B, et al (2018b) Sweat-from gland to skin surface -

606 production, transport and skin absorption. J Appl Physiol japplphysiol.00872.2017.

$607 \quad$ doi: $10.1152 /$ japplphysiol.00872.2017

608 Harvey BJ, Higgins M (2000) Nongenomic effects of aldosterone on Ca2+ in M-1

609 cortical collecting duct cells. Kidney Int 57:1395-1403. doi: 10.1046/j.1523-

$610 \quad$ 1755.2000.00981.x

611 Hegarty J, Harvey BJ (1998) Aldosterone increases intracellular calcium in cultured

612 human sweat gland epithelial cells by a non-genomic mechanism of action. J Physiol

$613 \quad 511 P$

614 Hew-Butler T, Hummel J, Rider BC, Verbalis JG (2014) Characterization of the effects

615 of the vasopressin V2 receptor on sweating, fluid balance, and performance during

616 exercise. Am J Physiol Regul Integr Comp Physiol 307:R366-75. doi:

$617 \quad 10.1152$ ajpregu.00120.2014

618 Hew-Butler T, Noakes TD, Soldin SJ, Verbalis JG (2010) Acute changes in arginine

619 vasopressin, sweat, urine and serum sodium concentrations in exercising humans:

620 does a coordinated homeostatic relationship exist? Br J Sports Med 44:1710-715.

621 doi: $10.1136 /$ bjsm.2008.051771

622 Inoue Y (1996) Longitudinal effects of age on heat-activated sweat gland density and

623 output in healthy active older men. Eur J Appl Physiol Occup Physiol 74:72-77. doi:

$624 \quad 10.1007 / \mathrm{BF} 00376497$

625 Inoue Y, Nakao M, Ishizashi $\mathrm{H}$, et al (1998) Regional differences in the $\mathrm{Na}+$ 
627 Johnson RE, Pitts GC, Consolazio FC (1944) Factors influencing chloride concentration

628 in human sweat 1. Am J Physiol 141:575-589. doi: 10.220.33.3

629 Kenefick RW, Cheuvront SN, Elliott LD, et al (2012) Biological and analytical variation 630 of the human sweating response: implications for study design and analysis. Am J Physiol Regul Integr Comp Physiol 302:252-258. doi:

Kirby CR, Convertino VA (1986) Plasma aldosterone and sweat sodium concentrations after exercise and heat acclimation. J Appl Physiol 61:967-70

Machado-Moreira CA, Edkins E, Iabushita AS, et al (2009) Sweat gland recuitment following thermal and psychological stimuli. In: Castellini JW (ed) 13th International Conference of Environental Ergonomics

Mekjavic IB, Rempel ME (1990) Determination of esophageal probe insertion length based on standing and sitting height. J Appl Physiol 69:376-379. doi: 10.1152/jappl.1990.69.1.376

Nadel ER, Bullard RW, Stolwijk JA (1971) Importance of skin temperature in the regulation of sweating. J Appl Physiol 31:80-87

643 Reddy M, Quinton P (2003) Functional interaction of CFTR and ENaC in sweat glands.

644 Pflügers Arch - Eur J Physiol 445:499-503. doi: 10.1007/s00424-002-0959-x

645 Robinson S, Gerking SD, Tuerell ES, Kincaid RK (1985) Effects of skin temperature of 646 salt concentration of sweat. J Appl Physiol 2:654-62

647 Ruff RL (1999) Effects of temperature on slow and fast inactivation of rat skeletal muscle 648 $\mathrm{Na}(+)$ channels. Am J Physiol 277:C937-47

649 Sato K (1977) The physiology, pharmacology, and biochemistry of the eccrine sweat 650 gland. Springer Berlin Heidelberg, pp 51-131 
651 Shamsuddin AKM, Kuwahara T, Oue A, et al (2005a) Effect of skin temperature on the 652 ion reabsorption capacity of sweat glands during exercise in humans. Eur J Appl 653 Physiol 94:442-447. doi: 10.1007/s00421-005-1354-z

654 Shamsuddin AKM, Yanagimoto S, Kuwahara T, et al (2005b) Changes in the index of 655 sweat ion concentration with increasing sweat during passive heat stress in humans.

656 Eur J Appl Physiol 94:292-297. doi: 10.1007/s00421-005-1314-7

657 Smith CJ, Havenith G (2012) Body mapping of sweating patterns in athletes: A sex 658 comparison. Med Sci Sports Exerc 44:2350-2361. doi:

$659 \quad$ 10.1249/MSS.0b013e318267b0c4

660 Stolwijk JA, Hardy JD (1966) Partitional calorimetric studies of responses of man to 661 thermal transients. J Appl Physiol 21:967-977

662 Thomas PE, Korr IM (1957) Relationship between sweat gland activity and electrical 663 resistance of the skin. J Appl Physiol 10:505-510

664 Yoshida T, Shin-ya H, Nakai S, et al (2006) Genomic and non-genomic effects of 665 aldosterone on the individual variation of the sweat $\mathrm{Na}+$ concentration during 666 exercise in trained athletes. Eur J Appl Physiol 98:466-471. doi: 10.1007/s00421667 006-0295-5

668

669

670 Figures and Tables 


\begin{tabular}{|c|c|c|c|c|c|c|c|c|c|c|c|}
\hline & & BL & 5 & 10 & 15 & 20 & 25 & 30 & 35 & 40 & 45 \\
\hline \multirow{2}{*}{$\begin{array}{l}\mathrm{HR} \\
\text { (bpm) }\end{array}$} & Neutral-Warm & $\begin{array}{l}61.3 \\
\pm 8.7\end{array}$ & $\begin{array}{c}65.5 \\
\pm 6.9\end{array}$ & $\begin{array}{c}67.9 \\
\pm 8.4\end{array}$ & $\begin{array}{l}72.7 \\
\pm 8.8\end{array}$ & $\begin{array}{l}77.0 \\
\pm 7.1\end{array}$ & $\begin{array}{c}78.2 \\
\pm 9.4\end{array}$ & $\begin{array}{c}79.2 \\
\pm 10.8\end{array}$ & $\begin{array}{c}82.5 \\
\pm 11.3\end{array}$ & $\begin{array}{c}86.9 \\
\pm 10.7\end{array}$ & $\begin{array}{l}89.9 \\
\pm 10.6\end{array}$ \\
\hline & Neutral-Cool & $\begin{array}{r}61.9 \\
\pm 8.1\end{array}$ & $\begin{array}{l}65.6 \\
\pm 8.7\end{array}$ & $\begin{array}{r}67.0 \\
\pm 9.9\end{array}$ & $\begin{array}{c}72.2 \\
\pm 7.1\end{array}$ & $\begin{array}{c}78.4 \\
\pm 7.0\end{array}$ & $\begin{array}{r}79.7 \\
\pm 7.7\end{array}$ & $\begin{array}{c}81.1 \\
\pm 8.1\end{array}$ & $\begin{array}{c}84.3 \\
\pm 8.0\end{array}$ & $\begin{array}{l}88.6 \\
\pm 8.1\end{array}$ & $\begin{array}{l}91.4 \\
\pm 8.9\end{array}$ \\
\hline \multirow{2}{*}{$\begin{array}{l}\text { MAP } \\
(\mathrm{mmHg})\end{array}$} & Neutral-Warm & $\begin{array}{l}93.9 \\
\pm 6.8\end{array}$ & $\begin{array}{l}98.9 \\
\pm 10.6\end{array}$ & $\begin{array}{l}99.1 \\
\pm 8.8\end{array}$ & $\begin{array}{l}99.8 \\
\pm 9.6\end{array}$ & $\begin{array}{l}101.5 \\
\pm 9.6\end{array}$ & $\begin{array}{l}100.4 \\
\pm 9.9\end{array}$ & $\begin{array}{l}97.4 \\
\pm 6.8\end{array}$ & $\begin{array}{l}99.7 \\
\pm 8.5\end{array}$ & $\begin{array}{l}99.4 \\
\pm 6.4\end{array}$ & $\begin{array}{l}97.3 \\
\pm 6.8\end{array}$ \\
\hline & Neutral-Cool & $\begin{array}{l}95.1 \\
\pm 7.1\end{array}$ & $\begin{array}{l}98.3 \\
\pm 7.6\end{array}$ & $\begin{array}{l}99.7 \\
\pm 9.7\end{array}$ & $\begin{array}{l}99.2 \\
\pm 8.5\end{array}$ & $\begin{array}{l}96.8 \\
\pm 8.7\end{array}$ & $\begin{array}{l}97.8 \\
\pm 8.7\end{array}$ & $\begin{array}{l}98.9 \\
\pm 8.9\end{array}$ & $\begin{array}{l}99.9 \\
\pm 8.5\end{array}$ & $\begin{array}{l}99.5 \\
\pm 8.5\end{array}$ & $\begin{array}{l}101.5 \\
\pm 7.4\end{array}$ \\
\hline \multirow{3}{*}{$\begin{array}{l}\text { CVC } \\
(\%)\end{array}$} & Warm & $\begin{array}{l}100.0 \\
\pm 0.0\end{array}$ & $\begin{array}{c}143.0 \\
\pm 97.2\end{array}$ & $\begin{array}{c}205.0 \\
\pm 158.2\end{array}$ & $\begin{array}{c}351.5 \\
\pm 291.0\end{array}$ & $\begin{array}{c}480.2 \\
\pm 310.8\end{array}$ & $\begin{array}{c}578.0 \\
\pm 304.9\end{array}$ & $\begin{array}{l}620.5 \\
\pm 301.7\end{array}$ & $\begin{array}{c}643.4 \\
\pm 288.7\end{array}$ & $\begin{array}{c}648.8 \\
\pm 298.5\end{array}$ & $\begin{array}{c}655.0 \\
\pm 310.1\end{array}$ \\
\hline & Neutral & $\begin{array}{l}100.0 \\
\pm 0.0\end{array}$ & $\begin{array}{l}120.5 \\
\pm 42.7\end{array}$ & $\begin{array}{c}159.8 \\
\pm 59.9\end{array}$ & $\begin{array}{c}252.4 \\
\pm 129.5\end{array}$ & $\begin{array}{l}384.7 \\
\pm 163\end{array}$ & $\begin{array}{c}460.8 \\
\pm 173.0\end{array}$ & $\begin{array}{c}524.7 \\
\pm 170.3\end{array}$ & $\begin{array}{c}601.7 \\
\pm 200.7\end{array}$ & $\begin{array}{c}645.6 \\
\pm 212.3\end{array}$ & $\begin{array}{c}663.6 \\
\pm 232.8\end{array}$ \\
\hline & Cool & $\begin{array}{l}100.0 \\
\pm 0.0\end{array}$ & $\begin{array}{l}101.4 \\
\pm 19.1\end{array}$ & $\begin{array}{c}120.4 \\
\pm 35.0\end{array}$ & $\begin{array}{r}165.4 \\
\pm 51.9\end{array}$ & $\begin{array}{c}224.9 \\
\pm 79.4\end{array}$ & $\begin{array}{l}281.6 \\
\pm 74.5\end{array}$ & $\begin{array}{l}357.1 \\
\pm 105.6\end{array}$ & $\begin{array}{c}464.5 \\
\pm 114.0\end{array}$ & $\begin{array}{c}590.9 \\
\pm 180.9\end{array}$ & $\begin{array}{c}645.5 \\
\pm 215.7\end{array}$ \\
\hline
\end{tabular}

Table 1: Cardiovascular responses measured continuously and averaged over 5 minutes during the passive heating protocol. There were no differences in heart rate (HR) or mean arterial pressure (MAP) between the Neutral-Warm and Neutral-Cool conditions ( $\mathrm{p}>0.05)$. There were no differences in CVC between both Neutral $\left(33^{\circ} \mathrm{C}\right)$ conditions (Neutral-Warm and Neutral-Cool), Cool $\left(30^{\circ} \mathrm{C}\right)$, or Warm $\left(36^{\circ} \mathrm{C}\right)$ conditions $(\mathrm{p}>0.05)$. All variables increased over time but there was no interaction effect $(\mathrm{p}>0.05)$. Values are based on 5-min averages and expressed as mean $\pm \mathrm{SD}$ for 10 participants. 


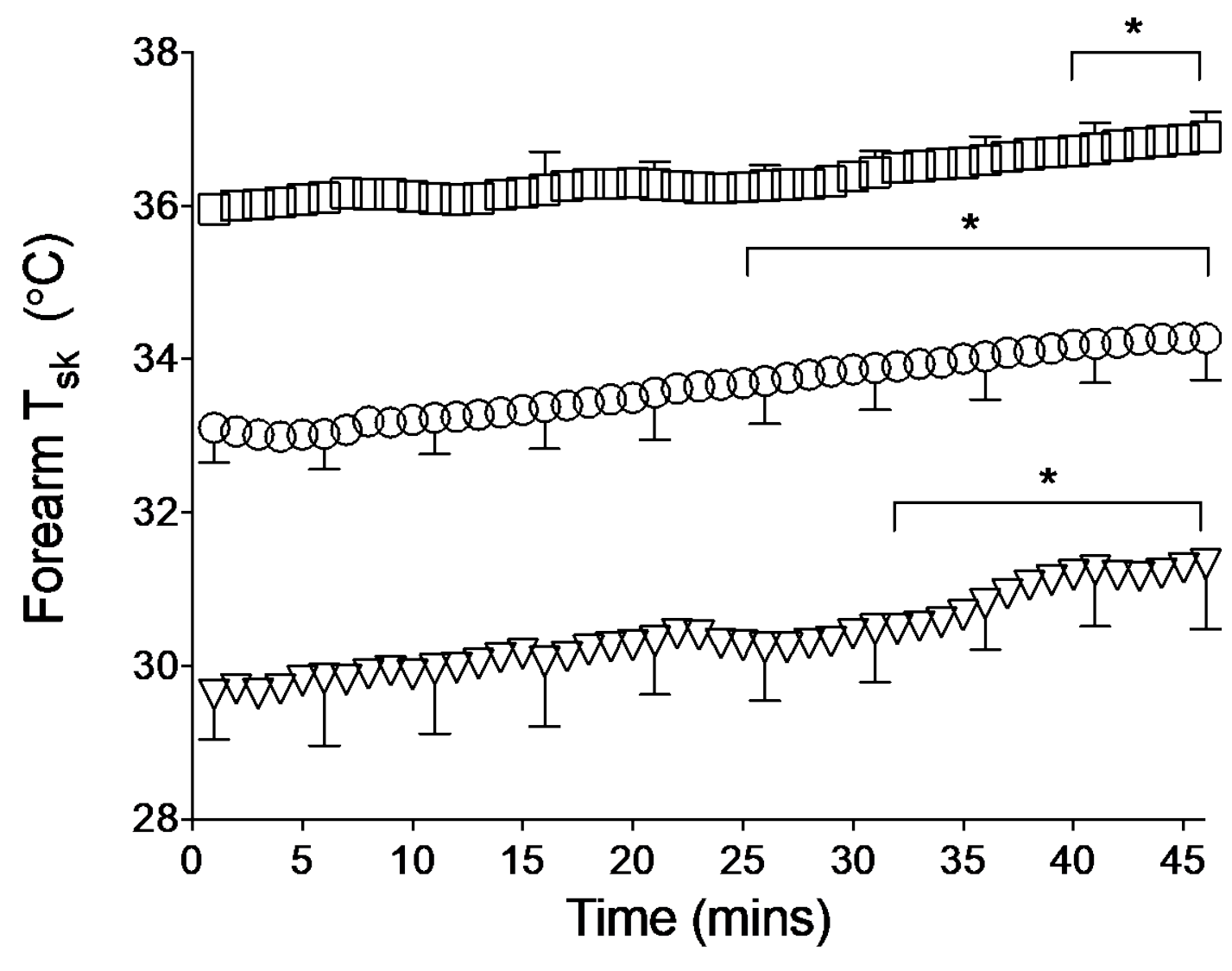

679 Figure 1: Local forearm skin temperature $\left(T_{\text {sk }}\right)$ measured whilst manipulating local $T_{\text {sk }}$ to $68036^{\circ} \mathrm{C}$ (Warm), $33^{\circ} \mathrm{C}$ (Neutral) and $30^{\circ} \mathrm{C}$ (Cool) during a 45-minute passive heating protocol. 681 Forearm $\mathrm{T}_{\text {sk }}$ was higher during Warm compared to both Neutral and Cool condition and 682 Neutral was also higher than the Cool condition $(p<0.05)$. Forearm $T_{\text {sk }}$ increased over time 683 in all conditions $(\mathrm{p}<0.05)$ and $*$ indicates when forearm $\mathrm{T}_{\mathrm{sk}}$ was higher than baseline from 684 each condition. The increases were similar between conditions; hence there was no 685 interaction effect between condition and time $(p>0.05)$. Values are based on 1-min 686 averages and expressed as mean \pm SD for 10 participants. To aid clarity error bars are 687 provided at 5-min intervals. 


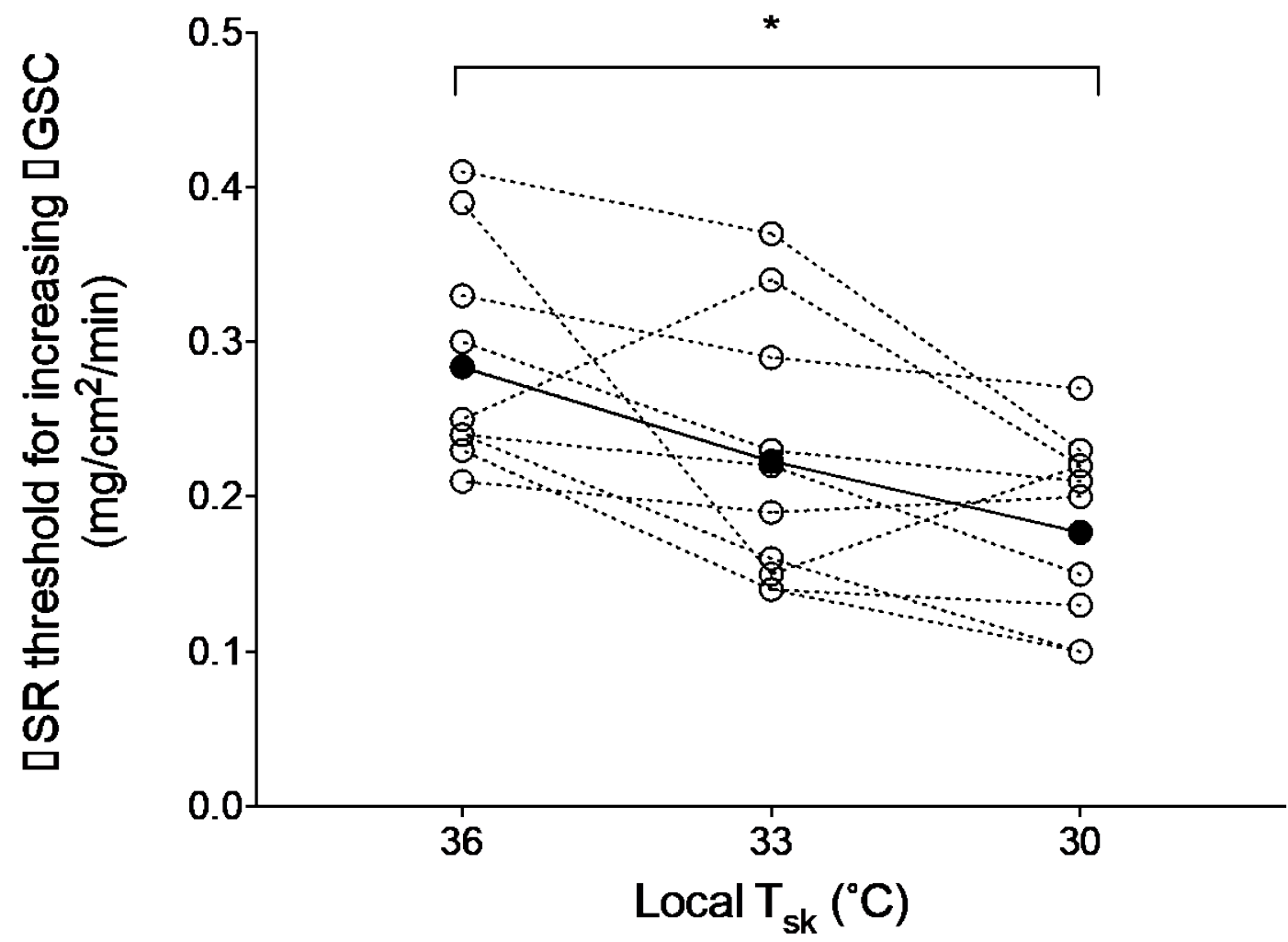

688

689 Figure 2: The relation between local $\mathrm{T}_{\text {sk }}$ and the $\Delta \mathrm{SR}$ threshold for an increasing $\Delta \mathrm{GSC}$.

690 The solid line and black cycle represent the mean data $(n=10)$, whilst the dashed line and 691 empty circles are the individual responses. Warm was significantly higher than Cool (* 692 indicates $\mathrm{p}>0.05)$ 

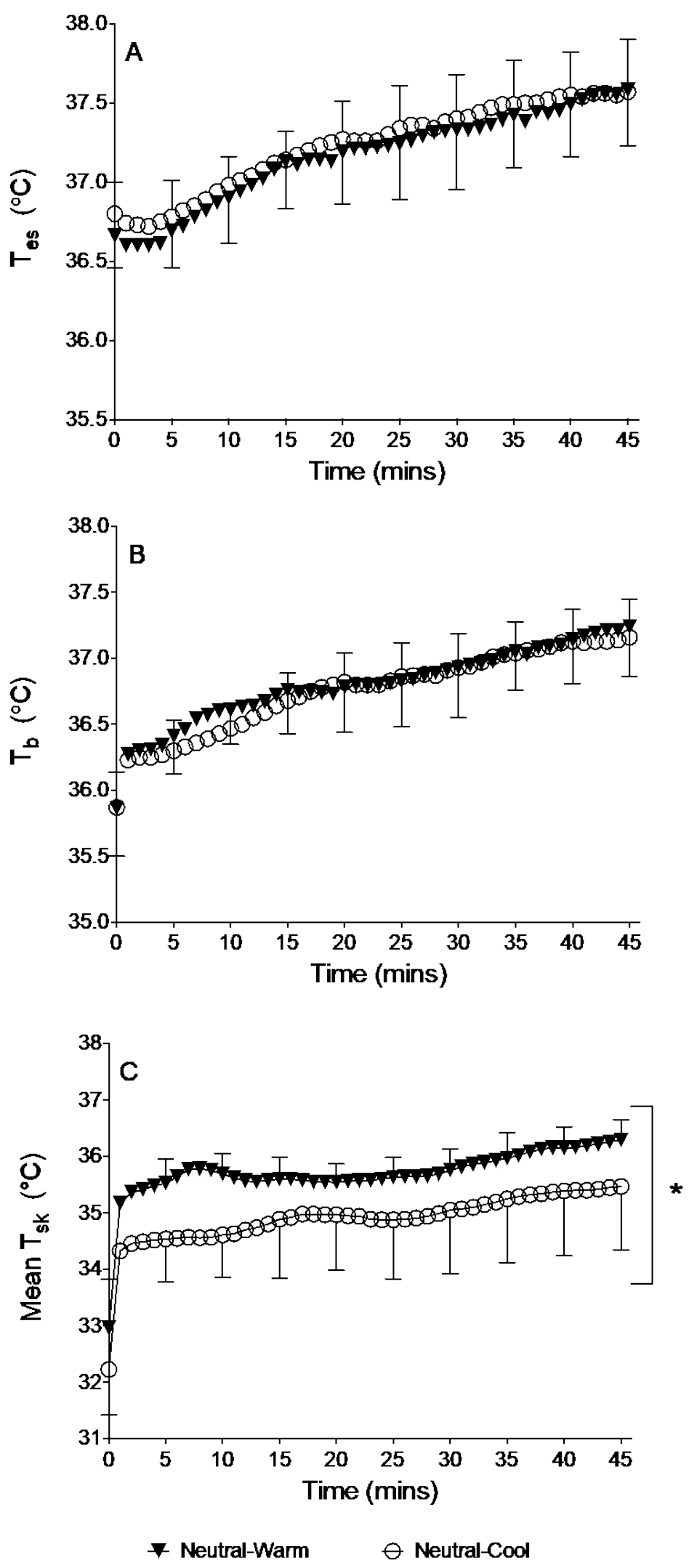

693

694 Figure 3: Esophageal temperature $\left(\mathrm{T}_{\mathrm{es}}\right)(\mathrm{A})$, body temperature $\left(\mathrm{T}_{\mathrm{b}}\right)(\mathrm{B})$ and mean skin 695 temperature $\left(\mathrm{T}_{\text {sk }}\right)(\mathrm{C})$ during the 45-minute passive heating protocol when local forearms 696 skin temperature were stimulated to be Neutral and Warm or Neutral and Cool. There were 
697 no significant differences found between conditions for $T_{\text {es }}$ or $T_{b}$ and whilst they both 698 increased over time there was no interaction effect $(\mathrm{p}>0.05)$. Mean $\mathrm{T}_{\text {sk }}$ was higher during 699 the Neutral-Warm compared to Neutral-Cool conditions $\left({ }^{*} \mathrm{p}<0.05\right)$ likely due to differences 700 in local forearm $T_{\text {sk }}$ as all other skin sites were not different $(p>0.05)$. Mean $T_{\text {sk }}$ increased 701 over time $(p<0.05)$ but this was similar between conditions $(p>0.05)$. Values based on 1702 min averages and are expressed as mean \pm SD for 10 participants. To aid clarity error bars 703 are provided at 5-min intervals.

704
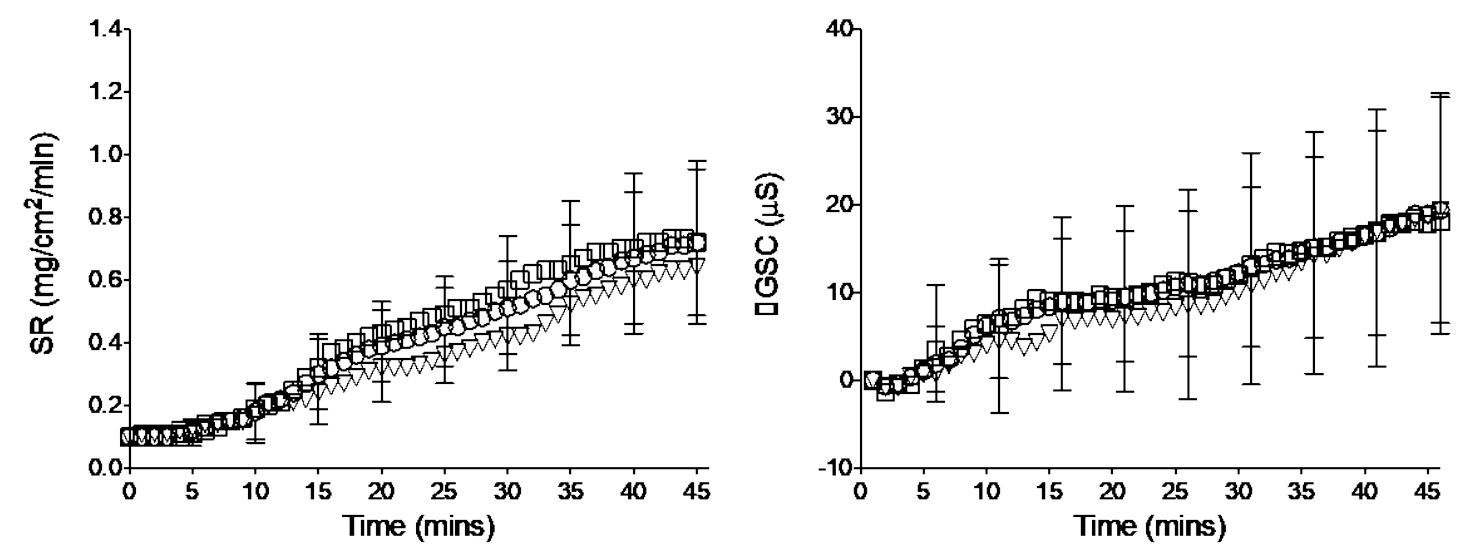

705 Figure 4: Local sweat rate (SR) (left) and $\triangle$ GSC (right) measured whilst stimulating local $706 \mathrm{~T}_{\text {sk }}$ at $36^{\circ} \mathrm{C}(\mathrm{Warm}), 33^{\circ} \mathrm{C}(\mathrm{Neutral})$ and $30^{\circ} \mathrm{C}(\mathrm{Cool})$ during a 45 -minute passive heating 707 protocol. SR was significantly different between all conditions $(p<0.05)$ and whilst SR 708 increases over time the increase was similar between conditions (no interaction effect, $709 \mathrm{p}>0.05$ ). There were no differences in $\Delta \mathrm{GSC}$ between conditions ( $\mathrm{p}>0.05$ ). Whilst $\Delta \mathrm{GSC}$ 710 increased over time the increase was similar between conditions (no interaction effect, $711 \mathrm{p}>0.05)$. Values are based on 1-min averages and expressed as mean \pm SD for 10 712 participants. To aid clarity error bars are provided at 5-min intervals.

713

714 